\title{
Analysis of Marketing Problems and Countermeasures of Small and Medium Enterprises
}

\author{
Lili Tian \\ Chongqing Youth Vocational and Technical College, Chongqing, 400715,China
}

Key words: Marketing, Enterprise, Market, Medium, Small.

\begin{abstract}
Information technology and the tide of economic globalization impact external operating environment of small and medium enterprises (SMEs) so that supply-demand relationship changes greatly in a short term. Oversupply has become the mainstream trend of market. SMEs generally bear huge marketing pressure. To adapt fierce competition environment, it is required to actively improve marketing, let customers know and understand commodity information through multiple channels including commodity property, function and feature etc, and make sure enterprises can know consumer demand in marketing campaign. Then, commodities and services are improved so that consumers can generate deep impression on commodities or services, approve marketing campaign mentally. In this way, commodity marketing scope can expand. This paper proposes corresponding countermeasures for marketing problem, including applying modern marketing planning idea, innovating marketing mode based on market demand and enhancing management of enterprise marketing risks.
\end{abstract}

\section{Introduction}

SMEs occupy an important position in multiple fields such as commodity circulation, food service and industrial production. At present, they are entering science and education field, traffic field and energy field. The number of SMEs is huge, so they can create large quantities of job opportunities and industries output value. The positions they offer account for 55\% 78\%. Industrial output value they contribute to exceeds 50\%. Thus, the existence and development of SMEs are rational, and they also the important force to support rapid development of national economy ${ }^{[1]}$. Relative to large enterprises, SMEs in China have poor foundation, poor financing ability, economic strength and economic scale. They are faced with the operating environment with diversified risks and strong uncertainty. Besides, the seller' s market gradually becomes the buyer' s market. To avoid business failure, SMEs must put marketing in the very important place, clearly know the problems in marketing and find out corresponding countermeasures.

\section{Problems}

Marketing problems of SMEs mainly include the following. Firstly, they cannot effectively implement modern marketing planning concept, and their marketing planning ability is low. Marketing concept guides marketing planning activity. If the wrong marketing concept cannot be corrected, and it is believed that marketing is short-term selling behavior rather than long-term investment behavior, enterprise marketing planning ability will decrease. The concrete manifestations are as follows. Marketing scheme is divorced from reality; external environment does not support marketing scheme, so scheme execution difficulty increases; the short-term goal and long-term goal of marketing cannot be unified and even contradict each other ${ }^{[2-3]}$. The ivory-towered marketing scheme cannot gain cooperation and support of suppliers and dealers, and it is also difficult for consumers to approve the marketing campaign. Thus, disconnection between external environment and marketing work may occur anytime. Future market cannot be accurately judged in the process of planning scheme execution. The objective of scheme execution is not explicit, either. When short-term goal and long-term goal of marketing work contradict each other, sacrificing 
long-term benefit and excessively pursing recent and realistic benefits may occur easily. Secondly, marketing mode lacks innovation, which is also a major problem faced by SMEs. At present, marketing mode adopted by SMEs include network marketing, television marketing and brand marketing etc. Traditional network marketing channels include network advertising, sending email to target group and establishing enterprise website etc. Television marketing mainly refers to TV advertising. Brand marketing contains chain store, franchisee, original equipment manufacturer (OEM) or setup of self-owned brand etc. Other marketing modes include magazine marketing, low price promotion, newspaper marketing, brochure and professional sales exhibition etc. The above marketing modes are directly copied or stiffly imitated, and lack certain originality. SMEs not just waste the cost in marketing work, but also are hard to gain competitive advantage in market. Consumers cannot get unique experience in marketing campaign. It is hard for marketing work to bring economic benefit. In addition, poor marketing risk management is also a problem which needs to be solved urgently. If marketing risks cannot be effectively reduced or avoided, enterprise operation may be seriously affected, and enterprise lifetime may be shortened.

\section{Countermeasures}

\section{To apply modern marketing planning concept}

To improve marketing planning ability of SMEs, it is required to pay attention to applying modern marketing planning concept. Aiming at the market environment faced by SMEs, dialectic marketing planning concept should be applied first, and marketing work should be implemented on the basis of subdividing customer value. Iron-type customers, silver-type customers, copper-type customers and gold-type customers can be divided according to current consumption situation and consumption appreciation potential in marketing work. Different marketing planning idea should be applied for different customers ${ }^{[4]}$. For iron-type customers with low appreciation potential and current value, consumption potential may be properly mined in marketing work, and product information may be issued through network marketing with low maintenance cost. Meanwhile, considerate marketing service can be applied to let customers gain fresh consumption experience. For copper-type customers with high appreciation potential and low current value, customer relation improvement should serve as the purpose of marketing planning to enhance customers' consumption ability. Brand building should be valued in marketing planning. The brands with good reputation and good product quality can be used to attract customers, let customers generate selection preference for the brands and improve customers' brand loyalty . besides, personalized services can be offered for copper-type customers, such as costume design, health consultation and financial management service. Multiple approaches may be used to keep contact with customers. Shopping coupons, merchandise news magazine and photo album may be offered for customers. For silver-type customers, purchase privilege should be offered for them in marketing planning so that customers can gain satisfaction. For example, for those customers with large quantities of purchase or purchase for long time, rebate and other special preference may be offered. At the same time, interactive marketing scheme may be applied so that customers can sellers entertain together and exchange. For gold-type customers, specially-assigned persons should be arranged to offer marketing services, and marketing scheme should be planned on the basis of following the principles of "effective communication, fast service and effective incentive" [5]. Moreover, knowledge marketing planning concept should be applied in enterprises, and planning concept should be gradually changed according to customers' demand for knowledge. For instance, in terms of consumption existence form guidance, practical demand guidance should be changed to coexistence guidance of potential demand and practical demand. In terms of consumption structure guidance, material guidance should be gradually changed to spiritual guidance; in terms of service connotation and commodity connotation, business information communication should be gradually changed to business culture guidance. 


\section{To innovate marketing mode according to market demand}

During innovating marketing mode of SMEs, market requirement should be considered. Meanwhile, agility innovation principle should be adhered to. Firstly, new social media and information platform should be applied for marketing. For instance, in the aspect of network marketing, the user base of Wangxin, WeChat and QQ etc. is large, and the viscosity is strong, so they may be used as marketing tools. Besides, marketing may be conducted in combination of search engines with strong flexibility, convenient valuation, high positioning precision, low cost and extensive audiences. Secondly, marketing system should be applied to manage marketing work and customer information to make sure dealer information, supplier information and customer demand information can be gained in time in the marketing system. Data information flow should be applied to analyze the changes of marketing environment, integrate marketing resources and master marketing opportunity in time. In addition, it is required to maintain vigilance for the events which continue to ferment in social media, and the enterprise products can be marketed with the help of fermentation event, such as automobile data recorder marketing for automobile blackmail ${ }^{[6]}$. Thirdly, advertisement implantation method may be applied for marketing. Since network marketing cost is low, most SMEs tend to release promotion information for network marketing. However, the promotion information has no attraction at all usually, and even makes target customers generate boredom. Besides, network marketing audiences have more options, and can avoid passive acceptance of marketing information bomb. Thus, the carriers with strong enjoyment (such as network play and network video) may be chosen to implant brand advertising, product information or enterprise information. During advertising implantation, the principle of entertaining the public should be followed. Meanwhile, it is required to rationally choose implantation mode and control implantation frequency so that the audiences can unconsciously accept commodity information in the process of accepting knowledge or entertainment, take the lead to help communicate marketing information. Furthermore, experiential marketing mode can be applied. Experiential marketing brings enormous economic benefit for Apple Inc. SMEs can properly refer to experiential marketing to expand marketing channel. Experiential marketing activity can let customers directly experience service quality, test commodity quality, eliminate worry and doubt before purchase and cultivate customers' viscosity to enterprise services and products so as to effectively enhance the desire to buy ${ }^{[7]}$.

\section{To enhance management of enterprise marketing risks}

The marketing risks of SMEs mainly include product risk, price risk, promotion and distribution channel risk. To evade these risks, the following measures may be taken. Firstly, marketing environment should be investigated carefully. In product design stage, consumer group positioning stage and promotion stage, it is required to go deep into the market and carry out market survey to know customer demand and market share of competitors in time. Meanwhile, the latest economic situation, international politics, policy information and macroeconomic information should be collected. Based on grasping the firsthand information, marketing campaign should be planned with pertinence. If possible, marketing risk emergency exercise may be implemented to enhance the ability of SMEs to cope with marketing risks ${ }^{[8]}$. Moreover, when marketing risks happen, dependence, characteristic highlighting and supplementing omissions etc, should be taken in time to cope with risks and reduce loss. Dependence strategy refers to service supply for large enterprises so as to gain fund support of large enterprises and continuously accumulate force under the support of large enterprises. When dependence strategy is applied, SMEs should gradually improve the ability to develop products and market as well as operation level, and avoid loss of initiative and initiative. Characteristic highlighting refers to development of characteristic products or supply of characteristic services and implementation of marketing by proprietary technology or patented technology so as to size the target market as soon as possible and train target customers' loyalty in a short time. Supplementing omissions means to concentrate to operate the commodities with tiny profit, numerous varieties or small wholesale quantity, or operate the commodity or service field that large enterprises do not get involved in. 


\section{Case study}

A beverage company, founded in 2007, belongs to a small and medium private enterprise. Its main products include mountain spring water, purified water, peppermint water and other carbonated beverage. Beverage market competitions are fierce. Due to the impacts of domestic and overseas grand brands, beverage market share of this company gradually decreases. Thus, it urgently applies rational marketing strategy to improve market share. Marketing problems of this enterprise include non-scientific marketing concept, lack of marketing mode innovation, and irrational marketing strategy combination. To improve marketing work, the following measures are applied. Firstly, scientifically analyze marketing environment. In terms of political environment, enterprise product label and packaging comply with food policy provisions, so the products are permitted to enter food market. Besides, the products conform to local quality control standards of barreled water and bottled water. In the aspect of economic environment, GDP level in this area is higher than nationwide average level. In terms of cultural environment, consumers pay more attention to food safety issue than before. Mineral water beverage produced by this company is clean and healthy, with health care effect and broad market development prospect. Secondly, the following marketing modes are applied for marketing environment. The company signs cooperation agreement with professional research institute, and the research institute provides ingredient analysis report of spring water, issues ingredient and publicizes the functions of mountain spring water so as to improve trust and popularity of consumer group for mountain spring water. At the same time, the company modifies product packaging, highlights characteristics of mountain spring water, applies price reduction selling strategy in summer and properly increases the price in winter. Besides, the company flexibly adjusts the product price according to selling situations of exclusive stores and supermarkets. Based on market survey, the products are promoted in large and medium supermarkets with large visitor floe rate, and promotion strategy and advertising board are adjusted according to selling conditions in the supermarkets. The company properly adjusts the volume of bottled water, increase or decreases the production of beverage in accordance with season changes and market demand. Furthermore, distribution incentive mode may be applied to encourage distributors to promote sales of products to small supermarkets or convenience stores to make sure the products can overall cover consumer groups of different types.

\section{Conclusions}

In conclusion, marketing is fundamental guarantee for SMEs to develop and grow. It is required to pay attention to studying enterprise marketing situation, and formulate improvement measures for defects of marketing and market environment changes so as to effectively grasp market opportunity and create more profit space. During applying marketing strategies, it is also required to rationally choose the region according to marketing environment, overall consider resource factor, geographical factor and cultural factor about marketing so as to improve marketing effect on the basis of giving play to regional advantages. During formulating marketing scheme, the responses of the public, competitors, consumer group and supplier to marketing campaign should be analyzed to make sure marketing dedication can bring stronger competitive edge and industrial advantage for the enterprise, effectively extrude competitors and obtain stable development and long-term survival.

\section{Acknowledgement}

This paper is college teaching reform project: development and practice of group sharing course of commerce and trade specialty under background of university-enterprise cooperation - case study of Marketing course in Chongqing Youth Vocational and Technical College, 4069JG2016101 


\section{References}

[1] Wang Yuehui, Wang Li, Miao Qi, Influence of environmental uncertainty on dynamic marketing ability and its performance - empirical study based on 450 enterprise samples, System Engineering, 2015,33(4):53-61.

[2] Zhang Genming, Chen Pei, Influence of market orientation and entrepreneurial orientation on dual-element activity of SMEs under competitive environment, Science \& Technology Progress and Policy, 2015,32(3):80-84.

[3] Hu Junfeng, Chen Xiaofeng, Dynamic evolution of SME cluster innovation network under perspective of industrial transfer - example illustration from industrial park co-built in Jiangsu, Modern Economic Research, 2014(8):45-49.

[4] Zhu Fulin, Tao Qiuyan, Study on social network relationship for SME growth - case study of technology-based SME survey data in Beijing, Studies in Science of Science, 2014,32(10):1539-1545.

[5] Zhu Pingfang, Luo Xiang, Xiang Gede, Empirical study on innovation performance space overflow effect of SMEs in China - based on Marx's labor division and cooperation theory, The Journal of Quantitative \& Technical Economics, 2016(5):3-16.

[6] Yang Yi, Hou Ying, Study on SME financing performance based on four-dimensional comprehensive assessment system - financing difficulty fund cost, time efficiency and private financing, Financial Theory and Practice, 2015(2):18-24.

[7] Li Baizhou, Xu Guangyu, Su Yi, Study on formation mechanism of SME cooperation innovation behavior - explanatory framework based on planned behavior theory, Studies in Science of Science, 2014,32(5):777-786.

[8] Yao Yaojun, Dong Gangfeng, Development of small and medium banks and financing restraint of SMEs - empirical research under perspective of optimal financial structure theory of new structure economics, Journal of Finance and Economics, 2014,40(1):105-115. 